Neurosurg Focus 4 (2):Article 11, 1998.

\title{
Recombinant human morphogenetic protein: its future role in spinal fusions
}

\section{Thomas C. Chen, M.D., Ph.D.}

Departments of Neurosurgery and Pathology, University of Southern California, Los Angeles, California

The marriage of basic scientific research and clinical application often leads to profound advances in our understanding of various disease processes and how they may be ameliorated. One such fortuitous combination has been the discovery of bone morphogenetic proteins (BMPs) and their potential application in spinal fusions. The goal of this article is to introduce the neurosurgeon to the basic biology of this protein family, current experimental data (in vitro and in vivo models) demonstrating their effectiveness in enhancing bony fusions, and preliminary clinical trials utilizing BMP in long bone fusions. Using this information, a proposal for the use of BMP in spinal fusions under various clinical scenarios will be discussed.

\section{Key Words * human bone morphogenetic protein * spine * fusion}

\section{PURIFICATION AND CHARACTERIZATION OF BMP}

Marshall R. Urist, M.D., first coined the term bone morphogenetic protein (BMP). He attempted to reproduce bone formation in vivo by extracting what appeared to be a low-molecular-weight glycoprotein from demineralized rabbit tibia matrix, implanting it ectopically into rats and mice, and observing new bone formation.[28] In an in vivo rodent assay system, a substance is termed BMP if it can induce ectopic bone formation, which functions and responds to internal and external stimuli as typical endochondral bone.[21,29] Extensive characterization of this process indicates that it mirrors normal bone morphogenesis, consisting of invasion by migrating mesenchyme, which differentiates over a period of approximately 7 days into cartilage-forming cells (chondroblasts and chondrocytes). Bone cells (osteoblasts and osteoclasts) then appear in the area and are responsible for the gradual removal of cartilage and deposition of new bone. The end result is the replacement of the originally implanted material with an ossicle of new bone, complete with a fully functional marrow.[20]

The purification and characterization of this bone morphogenetic extract was a tedious process. Urist, et al.,[29] were able to use sodium dodecyl sulfate polyacrylamide gel electrophoresis to recover a 30-kD fraction, which, when reduced, yielded three individual polypeptides with sizes of 30,18, and $16 \mathrm{kD}$. This process represented a purification of approximately 300,000-fold, as $40 \mathrm{~kg}$ of bovine bone powder was necessary to produce $40 \mu \mathrm{g}$ of purified BMP. The amino acid sequence was then able to be derived from a highly purified preparation of BMP from bovine bone. Using recombinant DNA technology, 
Wozney, et al.,[32] were able to isolate human complementary DNA (cDNA) corresponding to the three polypeptides present in this BMP preparation. Protein expression of the recombinant human (rh) BMPs (designated BMP-1, BMP-2, and BMP-3) was subsequently achieved. The derived amino acid sequences of the three polypeptides showed that BMP-1 did not appear to be related to other known growth factors. However, BMP-2 and BMP-3 were related to the transforming growth factor-beta (TGF- $\beta$ ) family.[32]

Currently, more than 12 BMPs have been characterized, nine of which have been shown to induce ectopic bone formation in an in vivo assay system. [4] The BMPs may be divided into three sets based on their amino acid homologies: 1) BMP-3, 2) BMP-5, BMP-6, BMP-7, and 3) BMP-2, BMP-4. Wang, et al.,[31] have used recombinant DNA technology to purify and characterize rhBMP-2, produced by a Chinese hamster ovary cell line (Fig. 1). Moreover, they were able to demonstrate that BMP-2 alone was sufficient to induce bone formation in vivo. A dose-response and time-course study in which the rodent ectopic bone formation assay was used, demonstrated that implantation of 0.5 to $115 \mu \mathrm{g}$ of partially purified human BMP-2 was able to induce cartilage formation by Day 7 and bone formation by Day 14 . In all cases, the protein is synthesized with an amino-terminal propeptide region that is later cleaved off. Dimerization occurs intracellularly or on secretion, and mature BMP is secreted in an active form.[10] Like other TGF- $\beta$ proteins, BMP binds to a serine/threonine kinase receptor that is related to the kinase domain in TGF-B receptors.[1] Human recombinant BMP-2 is a 32-kD homodimeric glycoprotein, though heterodimers seem to exist in native BMP. Each monomer in the active form consists of 114 amino acids.[22]

\begin{tabular}{|c|c|c|}
\hline 1 & 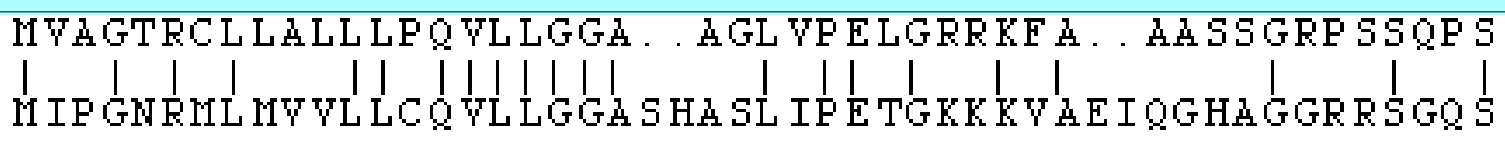 & 50 \\
\hline 47 & DEVL SEF E LRLL SMF GL KQRP TPSRD AVVPP YMLDL YR RH SG . . . . QP & 92 \\
\hline 51 & HELLRDF EATLQMF GLRR RPQPSKSAV I PDYMRDL YRLQSGEEEEEQ & 100 \\
\hline 93 & PAPDHRLERAASRANTVRSFHHEE SLEELPETSGKTTRRF FFNLSS & 142 \\
\hline 101 & STGLE YPERPASRANTVRSFHHEE HLENIPGTSENSAFRFLFNLSSIPE & \\
\hline 143 & EF ITSAELQVFR EQMQD AL GNNSSFHHR INI YE I IKPATANSKFP VTR & \\
\hline 151 & 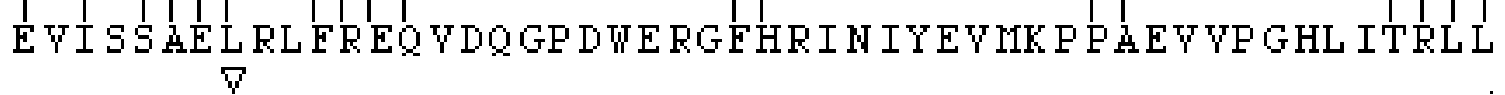 & \\
\hline 193 & VTP AVMRWTAQGHANHGFV VEVAHLEEKQGV & 242 \\
\hline 201 & 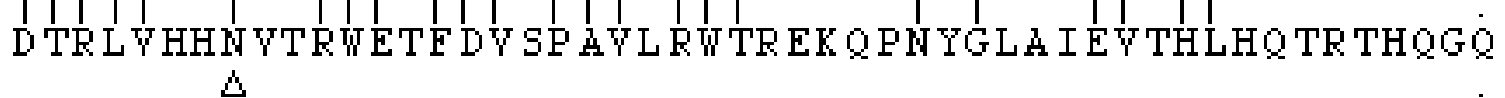 & \\
\hline 243 & HVR I SR SL HQDE HSW SQ IR PL L VTFGHDGKG HP LHKREKI & \\
\hline 251 & GHDGRGHALTRRRRAKR SPK HH & \\
\hline 289 & RKR LK SSCKR HP LY VDF SD VGWND W I P PGYHAF YCHGECF & \\
\hline 301 & KNKNCRRHS & \\
\hline 339 & KACCVPTEI & \\
\hline 351 & $\mathrm{STN}$ & \\
\hline 389 & VYEGCGCR & \\
\hline 401 & VVEGCGCR 408 & \\
\hline
\end{tabular}


Fig. 1. Amino acid sequence of cloned rhBMP-2.

\section{BMP Function: In Vitro Results}

As BMP induces bone formation, which involves the migration of undifferentiated mesenchymal cells, differentiation into cartilage, and subsequent bone replacement by osteoblasts and osteocytes, the effect of BMP on mesenchymal cells, chondrocytes, and osteoblasts may be studied in vitro. Most of the in vitro studies have been performed with rhBMP-2. Thies, et al.,[26] have examined the effect of rhBMP-2 on the osteoblastic differentiation of a bone marrow stromal cell line, W-20-17, a good model for mesenchymal stem cells. Functional parameters of osteoblastic differentiation include induction of alkaline phostastase activity and increase in osteocalcin synthesis, the only known bone-specific protein produced by osteoblasts.[15] Treatment of W-20-17 cells led to increased alkaline phosphatase activity 12 hours after treatment and induced measurable osteocalcin levels by four days.[26] Analysis of these results suggests that rhBMP-2 induces the expression of several markers associated with the osteoblast phenotype in W-20-17 cells and raises the possibility that rhBMP-2 may be involved in the differentiation of osteoblasts from progenitor cells residing in the bone marrow.[26] Yamaguchi, et al.,[33] have examined the effect of BMP-2 on two clonal cell lines of rat osteoblast-like cells with different differentiation stages, C26 and C20. The C26 is a potential osteoblast precursor cell line capable of differentiating into muscle cells and adipocytes; the C20 is a more differentiated osteoblastic cell line. In the less differentiated cell line $\mathrm{C} 26$, myogenetic differentiation was greatly inhibited by adding rhBMP-2, whereas, rhBMP-2 induced osteocalcin mRNA expression and its protein synthesis in C26 cells. In both cell lines, rhBMP-2 increased cyclic adenosine monophosphate production in response to parathyroid hormone. However, there was no increase in osteocalcin synthesis in the C20 cells.[33] In in vitro organ cultures of metatarsal long bones of mouse embryos, Dieudonné, et al.,[6] have demontrated that BMP-7 stimulated chondrogenesis, whereas TGF- $\beta$ inhibited it. Analysis of these in vitro studies demonstrates that BMP-2 clearly has differentiating and osteogenic properties for bone morphogenesis.

\section{BMP Function: In Vivo Results}

In vivo function of BMP may be derived from studies of organogenesis and fracture healing. In the developing chick limb, BMP-2 is involved in patterning, being expressed at the polarizing region of the limb, and this implicates its involvement in changes in limb polarization. Although BMP-2 does not appear to be the signal stimulus initiating changes in polarization, its expression appears to correlate with changes in anteroposterior position, suggesting that there is a close temporal and spatial relationship between BMP activation and polarizing region grafts.[8] Additionally, BMPs are involved in cartilage and bone formation during embryonic development. When BMP-4 was applied to cultured limb bud mesoderm, it stimulated cartilage formation as measured by incorporation of radioactive sulfate into sulfated proteoglycans.[5] There is evidence that BMPs are also involved in a variety of embryonic epithelial and mesenchymal tissues separate from the skeletal system. Lyons, et al.,[16] have demonstrated that BMP-2 RNA is expressed in a variety of embryonic epithelial and mesenchymal tissues outside of the developing skeletal system. Increased BMP-2 RNA is found in developing limb buds, heart, whisker follicles, tooth buds, and craniofacial mesenchyme.[16] Analysis of these results suggests that BMP-2 plays multiple roles in morphogenesis and pattern formation in the vertebrate embryo.

In a fracture repair model, BMP-2 and BMP-4 are present and have specific cellular localizations. In a murine rib model BMP-4 appears for a specific period 12 to 72 hours after fracture. It appears to initiate, 
promote, and maintain the chondrocyte phenotype.[17] On the other hand, BMP-2 is involved in the differentiation of osteoblasts from progenitor cells resident in the marrow.[20]

\section{BMP Function: Genetic Analysis}

Another method of inferring BMP function is to look at mutations of the BMP gene. Alterations in the BMP-2 gene, localized to chromosome 20 in humans, may contribute to the rare autosomal dominant condition called fibrodysplasia ossificans progressiva, an autosomal dominant trait in which the connective tissue septa of muscle are replaced by cartilage and bone.[18,30]

\section{PRELIMINARY DATA}

\section{In Vivo Animal Model Long Bone Fusions}

Yasko, et al.,[34] first demonstrated structural bone formation in an established rat segmental femoral defect model. They found a dose-related response to rhBMP-2 and that rhBMP-2 plus marrow yielded the highest union rates $(100 \%)$ and was superior to autogenous cancellous bone graft. Similar studies have been performed in the sheep femur, canine mandible, and rabbit tibia and ulna. In fact, healing of the canine mandibular defect showed the efficacy of rhBMP-2 in inducing bone formation in a bone that normally follows the intramembranous pathway.[27] The rabbit ulnar nonunion model gave further evidence for the ability of rhBMP-2 to heal larger defects.[3] Gerhart, et al.,[9] have examined the fusion of segmental femoral defects in sheep by using rhBMP-2. Four treatment groups were included: Group I, no implant; Group II, inactive bone matrix; Group III, rhBMP-2 mixed with inactive bone matrix; and Group IV, autogenous bone graft. Fusion was achieved in all animals treated with rhBMP-2 and inactive bone matrix. However, in animals treated without an implant or with inactive bone matrix alone fusion was not achieved. In all animals treated with autogenous bone graft fusion was achieved.[9]

\section{In Vivo Animal Model Spine Fusions}

Experimental spinal fusion using rhBMP-2 has been demonstrated to be effective. Schimandle, et al.,[25] have demonstrated that posterolateral intertransverse process arthrodeses may be enhanced with rhBMP-2. In their experiment, posterolateral fusions were performed at L5-6 in 56 rabbits using rhBMP-2 and autogenous bone graft. Solid fusion was demonstrated radiographically and by manual palpation in all rabbits implanted with rhBMP-2; only $42 \%$ of the autograft control fusions were solid. Moreover, there was a dose-dependent effect on the fusion as rabbits implanted with high-dose rhBMP-2 demonstrated more mature fusions with greater trabecular bone formation radiographically and histologically compared to rabbits implanted with low-dose rhBMP-2. Fusions were optimum when the rhBMP-2 was delivered in the collagen carrier during an autogenous bone graft.[25] Sandhu, et al.,[23] have demonstrated similar results using canine L4-5 intertransverse process fusions. Moreover, they demonstrated a plateau for increasing doses of rhBMP-2. Using a concentration-dependent curve of rhBMP-2 ranging from 58 to $920 \mu \mathrm{g}$, they demonstrated that fusion rates at the end of 3 months were identical for all the groups. The cross-sectional area of the fusion mass and mechanical stiffness of the L4-5 intersegment were not dose dependent. They concluded that no mechanical, radiographic, or histological differences occurred in the quality of intertransverse process fusion in the dose range of rhBMP-2 used. Moreover, in a subsequent experiment Sandhu, et al.,[24] demonstrated that there was no difference in spinal fusion in decorticated compared with nondecorticated spines at the higher rhBMP-2 concentrations ( 230 and $920 \mu \mathrm{g}$ rhBMP-2 vs. $58 \mu \mathrm{g}$ rhBMP-2, respectively). Recently, Fischgrund, et al.,[7] have demonstrated that various types of carrier media did not significantly affect the fusion rate in 
a canine fusion model. Using bone protein, Boden, et al.,[2] received similar results in both a rabbit and rhesus monkey model of posterolateral lumbar spinal fusion indicating that an osteoinductive growth factor is effective in a primate model.[2]

\section{Preliminary Clinical Trials of Long Bone Fusions}

Recombinant BMP has been used in limited clinical trials for treating resistant nonunions and partial or complete segmental defects of long bones. Most of the work has been published by Johnson, et al.,[11-14] from UCLA, in which they have examined a variety of resistant long bone nonunions, which have been resistant to conventional surgical fixation. Fractures included tibial nonunions, femoral nonunions, distal metaphyseal tibial nonunions, and a composite of long bone fractures that had been resistant to fusion. In the largest series, Johnson, et al.,[12] looked at 25 patients with resistant extremity fracture nonunions including partial or segmental defects. These patients were treated with a composite allograft implant of rhBMP-2 and autolyzed, antigen-free, allogeneic bone. Union was eventually achieved in 24 of 25 patients. Fusion was obtained even in patients with severely deformed nonunions of the distal end of the tibia, which had failed to respond to standard surgical methods. All of these cases of distal metaphyseal tibial nonunion were treated by open reduction, internal fixation, and rhBMP-2 implanted in absorbable gelatin capsules.[13]

\section{Future Use of rhBMP-2}

The use of rhBMP-2 to enhance spinal fusions holds tremendous promise for future applications in spine surgery. Currently, a trial of rhBMP-2 using interbody cages is in progress for anterior lumbar fusions. This trial is jointly sponsored by Sofamor-Danek (Memphis, TN) and Genetics Institute (Cambridge, MA). Future trials in which rhBMP-2 is used for posterolateral lumbar fusions and cervical fusions are also planned.

In the future, as the role of rhBMP-2 in spinal fusions becomes more defined, it will become increasingly useful in minimizing the current exposure and tissue trauma needed to perform a spinal fusion. For instance, in performing a posterolateral fusion, it has been our practice to decorticate the transverse processes before laying some autogenous cancellous bone for a bone graft. It may be possible with rhBMP-2 to avoid decortication of the transverse processes, and demineralized matrix such as Grafton may be used instead of performing a iliac crest graft for bone. Another possibility is in patients undergoing a lateral mass plate for cervical fusions. These patients currently often undergo harvesting of autogenous iliac crest or have some of their spinous processes removed in order to achieve bone fusion at the lateral masses and facets. If rhBMP-2 is used, then Grafton placed laterally may be sufficient to sustain a bony fusion. Another possible scenario for rhBMP-2 use may be in a patient who has undergone a lumbar fusion but develops pseudarthrosis at the next level up. It is conceivable that with rhBMP-2, these patients may not need to undergo a whole new procedure with extension of the posterolateral fusion. Instead, they may simply need an injection of rhBMP-2 at the pseudarthrosis site. Cages have been increasingly used for interbody fusions.[19] These configurations are made by packing cancellous bone into a titanium cage. Cages are now being placed laparoscopically as well as via an open exposure. Use of cages placed laparoscopically with rhBMP-2 and cancellous bone will minimize the invasiveness of an anterior fusion.

Recombinant human BMP-2 may also be used in patients who are at increased risk for not developing fusions. These include patients who are smokers and patients who have undergone multiple spine surgeries. Moreover, in cancer patients who develop metastatic lesions and require stabilization after a 
decompressive procedure, the use of rhBMP-2 to enhance their fusion is especially important, as these patients will undergo radiation therapy. The greater chance of a successful fusion in these patients may have a large impact on their subsequent quality of life. Future use of rhBMP-2 will lead to newer applications of this protein, which will hopefully lead to a better quality of life for our patients needing spinal fusion.

\section{References}

1. Attisano L, Wrana JL, Cheifetz S, et al: Novel activin receptors: distinct genes and alternative mRNA splicing generate a repertoire of serine/threonine kinase receptors. Cell 68:97-108, 1992

2. Boden SD, Schimandle JH, Hutton WC: The use of an osteoinductive growth factor for lumbar spinal fusion. Part II: Study of dose, carrier, and species. Spine 20:2633-2644, 1995

3. Bostrom M, Lane JM, Tomin E, et al: Use of bone morphogenetic protein-2 in the rabbit ulnar nonunion model. Clin Orthop 327:272-282, 1994

4. Celeste AJ, Iannazzi JA, Taylor RC, et al: Identification of transforming growth factor beta family members present in bone-inductive protein purified from bovine bone. Proc Natl Acad Sci USA 87:9843-9847, 1990

5. Chen P, Carrington JL, Hammonds RG, et al: Stimulation of chondrogenesis in limb bud mesoderm cells by recombinant human bone morphogenetic protein 2B (BMP-2B) and modulation by transforming growth factor $\beta_{1}$ and $\beta_{2}$. Exp Cell Res 195:509-515, 1991

6. Dieudonné SC, Semeins CM, Goei SW, et al: Opposite effects of osteogenic protein and transforming growth factor $\beta$ on chondrogenesis in cultured long bone rudiments. J Bone Min Res 9:771-780, 1994

7. Fischgrund JS, James SB, Chabot MC, et al: Augmentation of autograft using rhBMP-2 and different carrier media in the canine spinal fusion model. J Spinal Disord 10:467-472, 1997

8. Francis PH, Richardson MK, Brickell PM, et al: Bone morphogenetic proteins and a signalling pathway that controls pattering in the developing chick limb. Development 120:209-218, 1994

9. Gerhart TN, Kirker-Head CA, Kriz MJ, et al: Healing segmental femoral defects in sheep using recombinant human bone morphogenetic protein. Clin Orthop 293:317-326, 1993

10. Israel DI, Nove J, Kerns KM, et al: Expression and characterization of bone morphogenetic protein-2 in Chinese hamster ovary cells. Growth Factors 7:139-150, 1992

11. Johnson EE, Urist MR, Finerman GAM: Bone morphogenetic protein augmentation grafting of resistant femoral nonunions. A preliminary report. Clin Orthop 230:257-265, 1988

12. Johnson EE, Urist MR, Finerman GAM: Distal metaphyseal tibial nonunion. Deformity and bone loss treated by open reduction, internal fixation and human bone morphogenetic protein (hBMP). Clin Orthop 250:234-240, 1990

13. Johnson EE, Urist MR, Finerman GAM: Repair of segmental defects of the tibia with cancellous bone grafts augmented with human bone morphogenetic protein. Clin Orthop 236:249-257, 1988 
14. Johnson EE, Urist MR, Finerman GAM: Resistant nonunions and partial or complete segmental defects of long bones. Treatment with implants of a composite of human bone morphogenetic protein (BMP) and autolyzed, antigen-extracted, allogeneic (AAA) bone. Clin Orthop 277:229-237, 1992

15. Lian JB, Gundberg CM: Osteocalcin. Biochemical considerations and clinical applications. Clin Orthop 226:267-291, 1988

16. Lyons KM, Pelton RW, Hogan BL: Organogenesis and pattern formation in the mouse: RNA distribution patterns suggest a role for bone morphogenetic protein-2A (BMP-2A). Development 109:833-844, 1990

17. Nakase T, Nomura S, Yoshikawa H, et al: Transient and localized expression of bone morphogenetic protein 4 messenger RNA during fracture healing. J Bone Min Res 9:651-659, 1994

18. Rao VVN, Löffler C, Wozney JM, et al: The gene for bone morphogenetic protein 2A (BMP2A) is localized to human chromosome $20 \mathrm{p} 12$ by radioactive and nonradioactive in situ hybridization. Hum Genet 90:299-302, 1992

19. Ray CD: Threaded titanium cages for lumbar interbody fusions. Spine 22:667-680, 1997

20. Reddi AH: Bone and cartilage differentiation. Curr Opin Genet Dev 4:737-744, 1994

21. Riley EH, Land JM, Urist MR, et al: Bone morphogenetic protein-2: biology and applications. Clin Orthop 324:39-46, 1996

22. Sampath TK, Coughlin JE, Whetstone RM, et al: Bovine osteogenic protein is composed of dimers of OP-1 and BMP-2A, two members of the transforming growth factor-beta superfamily. J Biol Chem 265:13198-13205, 1990

23. Sandhu HS, Kanim LE, Kabo JM, et al: Effective doses of recombinant human bone morphogenetic protein-2 in experimental spinal fusion. Spine 21:2115-2122, 1996

24. Sandhu HS, Kanim LE, Toth JM, et al: Experimental spinal fusion with recombinant human bone morphogenetic protein-2 without decortication of osseous elements. Spine 22:1171-1180, 1997

25. Schimandle JH, Boden SD, Hutton WC: Experimental spinal fusion with recombinant human bone morphogenetic protein-2. Spine 20:1326-1337, 1995

26. Thies RS, Bauduy M, Ashton BA, et al: Recombinant human bone morphogenetic protein-2 induces osteoblastic differentiation in W-20-17 stromal cells. Endocrinology 120:1318-1324, 1992

27. Toriumi DM, Kotler HS, Luxenberg DP, et al: Mandibular reconstruction with a recombinant bone-inducing factor. Functional, histologic, and biomechanical evaluation. Arch Otolaryngol Head Neck Surg 117:1101-1112, 1991

28. Urist MR: Bone: formation by autoinduction. Science 150:893-899, 1965

29. Urist MR, Huo YK, Brownell AG, et al: Purification of bovine bone morphogenetic protein by hydroxyapatite chromatography. Proc Natl Acad Sci USA 81:371-375, 1984

30. Urist MR, Nakagawa M, Nakata N, et al: Experimental myositis ossificans: cartilage and bone formation in muscle in response to a diffusible bone matrix-derived morphogen. Arch Pathol Lab Med 
102:312-316, 1978

31. Wang EA, Rosen V, D'Alessandro JS, et al: Recombinant human bone morphogenetic protein induces bone formation. Proc Natl Acad Sci USA 87:2220-2224, 1990

32. Wozney JM, Rosen V, Celeste AJ, et al: Novel regulators of bone formation: molecular clones and activities. Science 242:1528-1534, 1988

33. Yamaguchi A, Katagiri T, Ikeda T, et al: Recombinant human bone morphogenetic protein-2 stimulates osteoblastic maturation and inhibits myogenic differentiation in vitro. J Cell Biol

113:681-687, 1991

34. Yasko AW, Lane JM, Fellinger EF, et al: The healing of segmental defects, induced by recombinant human bone morphogenetic protein (rhBMP-2). A radiographic, histological, and biomechanical study in rats. [published erratum appears in J Bone Joint Surg (Am) 73:1263-1271, 1991]. J Bone Joint Surg (Am) 74:659-670, 1992

Manuscript received January 16, 1998.

Accepted in final form January 23, 1998.

Address reprint requests to: Thomas C. Chen, M.D., Ph.D., 1200 North State Street, Suite 5046, Los Angeles, California 90033. 